NASA/TM-2005-213669

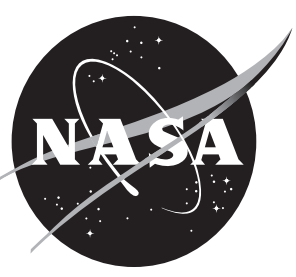

\title{
Flight Test Implementation of a Second Generation Intelligent Flight Control System
}

Peggy S. Williams-Hayes

NASA Dryden Flight Research Center

Edwards, California 


\section{NASA STI Program ... in Profile}

Since its founding, NASA has been dedicated to the advancement of aeronautics and space science. The NASA scientific and technical information (STI) program plays a key part in helping NASA maintain this important role.

The NASA STI program is operated under the auspices of the Agency Chief Information Officer. It collects, organizes, provides for archiving, and disseminates NASA's STI. The NASA STI program provides access to the NASA Aeronautics and Space Database and its public interface, the NASA Technical Report Server, thus providing one of the largest collections of aeronautical and space science STI in the world. Results are published in both non-NASA channels and by NASA in the NASA STI Report Series, which includes the following report types:

- TECHNICAL PUBLICATION. Reports of completed research or a major significant phase of research that present the results of NASA programs and include extensive data or theoretical analysis. Includes compilations of significant scientific and technical data and information deemed to be of continuing reference value. NASA counterpart of peer-reviewed formal professional papers but has less stringent limitations on manuscript length and extent of graphic presentations.

- TECHNICAL MEMORANDUM. Scientific and technical findings that are preliminary or of specialized interest, e.g., quick release reports, working papers, and bibliographies that contain minimal annotation. Does not contain extensive analysis.
- CONTRACTOR REPORT. Scientific and technical findings by NASA-sponsored contractors and grantees.

- CONFERENCE PUBLICATION. Collected papers from scientific and technical conferences, symposia, seminars, or other meetings sponsored or co-sponsored by NASA.

- SPECIAL PUBLICATION. Scientific, technical, or historical information from NASA programs, projects, and missions, often concerned with subjects having substantial public interest.

- TECHNICAL TRANSLATION. Englishlanguage translations of foreign scientific and technical material pertinent to NASA's mission.

Specialized services also include creating custom thesauri, building customized databases, and organizing and publishing research results.

For more information about the NASA STI program, see the following:

- Access the NASA STI program home page at http://www.sti.nasa.gov.

- E-mail your question via the Internet to help@sti.nasa.gov.

- Fax your question to the NASA STI Help Desk at (301) 621-0134.

- Phone the NASA STI Help Desk at (301) 621-0390.

- Write to: NASA STI Help Desk NASA Center for AeroSpace Information 7121 Standard Drive Hanover, MD 21076-1320 
NASA/TM-2005-213669

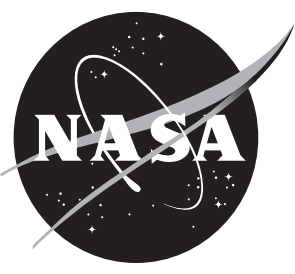

\section{Flight Test Implementation of a Second Generation Intelligent Flight Control System}

Peggy S. Williams-Hayes

NASA Dryden Flight Research Center

Edwards, California

National Aeronautics and

Space Administration

Dryden Flight Research Center

Edwards, California 93523-0273 


\section{NOTICE}

Use of trade names or names of manufacturers in this document does not constitute an official endorsement of such products or manufacturers, either expressed or implied, by the National Aeronautics and Space Administration.

Available from the following:

NASA Center for AeroSpace Information

7121 Standard Drive

Hanover, MD 21076-1320

(301) 621-0390
National Technical Information Service 5285 Port Royal Road

Springfield, VA 22161-2171

(703) 605-6000 


\begin{abstract}
The NASA F-15 Intelligent Flight Control System project team has developed a series of flight control concepts designed to demonstrate the benefits of a neural network-based adaptive controller. The objective of the team was to develop and flight-test control systems that use neural network technology, to optimize the performance of the aircraft under nominal conditions, and to stabilize the aircraft under failure conditions. Failure conditions include locked or failed control surfaces as well as unforeseen damage that might occur to the aircraft in flight. The Intelligent Flight Control System team is currently in the process of implementing a second generation control scheme, collectively known as "Generation 2" or "Gen 2," for flight testing on the NASA F-15 aircraft. This report describes the Gen 2 system as implemented by the team for flight test evaluation. Simulation results are shown which describe the experiment to be performed in flight and highlight the ways in which the Gen 2 system meets the defined objectives.
\end{abstract}

\title{
NOMENCLATURE
}

ARTS II airborne research test system computer

ASE aeroservoelastic

B neural network basis functions

$c_{1}, c_{2}, c_{3}, c_{4} \quad$ autopilot gain constants

dap roll stick input, in.

dep pitch stick input, in.

$d r p \quad$ rudder pedal input, in.

$e^{-x} \quad$ exponential function

$g \quad$ acceleration due to gravity, $9.8 \mathrm{~m} / \mathrm{s}^{2}$

$G \quad$ adaptation gain or learning rate

Gen 2 second generation of the IFCS program

$h \quad$ altitude, $\mathrm{ft}$

hdot time rate-of-change of altitude, $\mathrm{ft} / \mathrm{s}$

$h_{\text {ref }} \quad$ reference altitude, $\mathrm{ft}$

IFCS Intelligent Flight Control System

ILTV Inner-Loop Thrust-Vectoring program

$L \quad$ neural network dead band error

$\mathrm{n}_{\mathrm{y}} \quad$ lateral acceleration, $g$

$\mathrm{n}_{\mathrm{z}} \quad$ normal acceleration, $g$ 


$\begin{array}{ll}\text { NN } & \text { neural network } \\ p & \text { body axis roll rate, deg/s } \\ \text { PAL } & \text { pick-a-limit } \\ \text { PID } & \text { proportional, integral, and derivative } \\ \text { SCE } & \text { single computing element } \\ \text { SMLV } & \text { Structural Loads Model Validation } \\ \mathrm{U}_{\mathrm{e}} & \text { neural network error compensation term } \\ \mathrm{UAV} & \text { uninhabited aerial vehicle } \\ \text { VCAS } & \text { Versatile Control Augmentation System } \\ \mathrm{W} & \text { neural network weights } \\ \alpha & \text { angle of attack, deg } \\ \beta & \text { angle of sideslip, deg } \\ \beta \text {-dot } & \text { time rate-of-change of angle of sideslip, deg/s } \\ \delta_{\mathrm{a}} & \text { aileron deflection, deg } \\ \delta_{\mathrm{c}} & \text { canard deflection, deg } \\ \delta_{\mathrm{r}} & \text { rudder deflection, deg } \\ \delta_{\mathrm{s}} & \text { stabilator deflection, deg } \\ \phi & \text { bank angle, deg } \\ \Delta \mathrm{W} & \text { weight calculation from previous time-step } \\ \Delta \mathrm{t} & \text { summation symbol (sigma) } \\ \Pi & \end{array}$

\section{INTRODUCTION}

The NASA F-15 Intelligent Flight Control System (IFCS) project incorporates a series of flight control concepts designed to demonstrate the benefits of a neural network (NN)-based adaptive controller. The primary goal of the IFCS team is to demonstrate revolutionary control approaches that can optimize aircraft performance in both normal and failure conditions. These failure conditions encompass locked or failed control surfaces as well as unforeseen damage that might occur to the aircraft in flight. 
The IFCS team is currently in the process of implementing a second generation control algorithm, collectively known as "Gen 2," for flight testing on the NASA F-15 aircraft. The specific objectives for Gen 2 are to

- Implement and fly a direct adaptive neural network-based flight controller

- Demonstrate the ability of the system to adapt to simulated system failures in two ways

- By suppressing transients associated with the failure and

- By reestablishing sufficient control and handling of the vehicle for safe recovery

- Provide flight experience for development of verification and validation processes for flightcritical neural network software

This report describes the Gen 2 system as implemented by the IFCS team for flight test evaluation. Simulation results are shown which describe the experiment to be performed in flight and highlight the ways in which the Gen 2 system meets the defined objectives.

\section{Test Aircraft}

The test aircraft, NASA 837 shown in fig. 1, is a highly modified preproduction F-15B airplane and is not representative of production F-15 aircraft. Modifications to the vehicle include two canards mounted on the upper inlet area forward of the wing. The canards are modified F-18 horizontal tail surfaces, and their position in flight is scheduled to respond with angle of attack $(\alpha)$. An additional modification to the vehicle includes the incorporation of the F100-PW-229 Pratt \& Whitney (West Palm Beach, Florida) engines equipped with axisymmetric thrust vectoring nozzles. During flight test, the thrust vectoring capability is enabled, but the vectoring is commanded to zero. The airplane is controlled by a quadruplex, digital, fly-by-wire, flight control system. All mechanical linkages between the control stick, rudder pedals, and control surfaces have been removed from the aircraft. ${ }^{1}$

\section{Research Vehicle}

The research vehicle has five different types of control surfaces - canards, ailerons, stabilators, rudders, and flaps - each type having both a left and right surface. The canards are forward of the wing, the ailerons are part of the wing, stabilators are located on the back of the vehicle, and the rudders are located on the vertical tails. Flap position is commanded by the pilot to be either up or down, and this position is based on airspeed. 


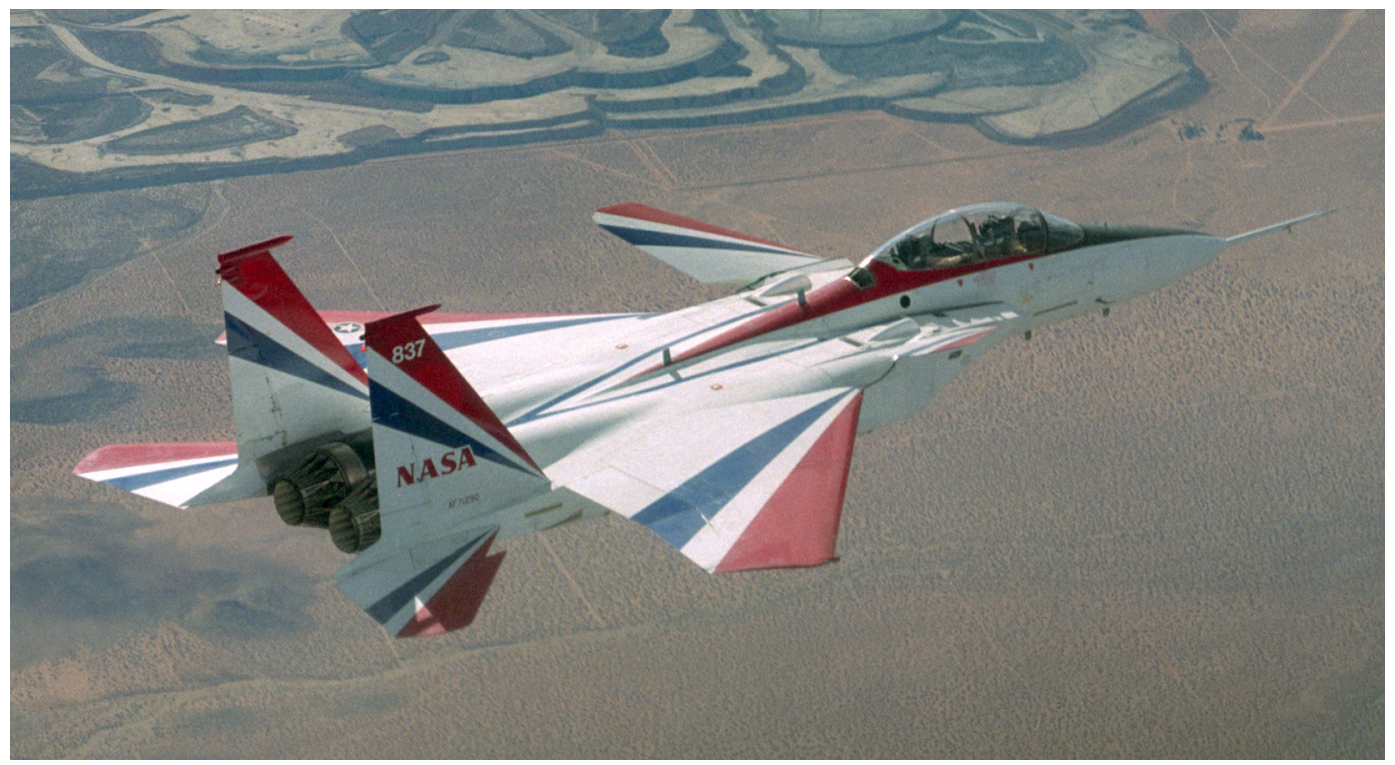

EC02-0281-2

Figure 1. NASA 837 F-15 airplane.

\section{INTELLIGENT FLIGHT CONTROL SYSTEM ARCHITECTURE}

Figure 2 shows the Gen 2 IFCS architecture. Gen 2 uses a direct adaptive control algorithm and has model inverse control with feedback error regulation and neural network augmentation. The underlying control scheme was developed by Dr. Anthony Calise and Byoung S. Kim of the Georgia Institute of Technology. ${ }^{2}$ NASA Ames Research Center implemented this control scheme in their Advanced Concepts Flight Simulator ${ }^{3}$ and performed extensive piloted evaluations for three different types of vehicles - a large transport aircraft, the NASA Dryden F-15 aircraft, and an uninhabited aerial vehicle (UAV). ${ }^{4}$

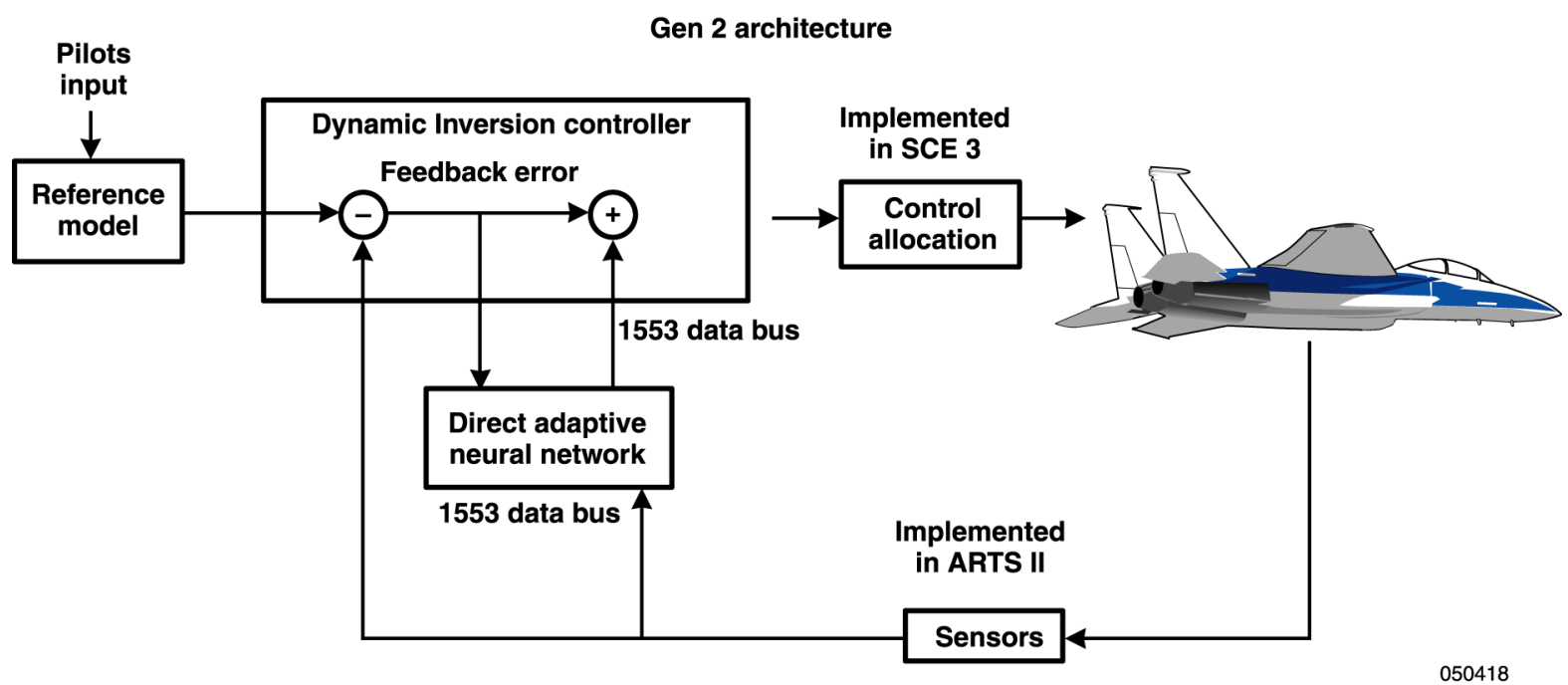

Figure 2. Gen 2 IFCS architecture. 


\section{Research Controller}

The research controller is a dynamic inversion-type controller and was originally developed by McDonnell Douglas Aircraft (St. Louis, Missouri). The baseline control laws were taken from the F-15 ACTIVE Inner-Loop Thrust Vectoring (ILTV) program, but the IFCS team has removed the thrust vectoring controls for the Gen 2 implementation. For the original dynamic inverse controller, the proportional, integral, and derivative (PID) gains were tuned to achieve linear stability robustness, aeroservoelastic (ASE) mode attenuation, and nonlinear system command following for the nominal (no failure) case.

While testing the original dynamic inverse controller with locked stabilator failure simulations, significant lateral acceleration $\left(\mathrm{n}_{\mathrm{y}}\right)$ and angle of sideslip $(\beta)$ excursions resulting from lateral stick inputs were noted. Because subsequent redesigns of the neural network were not able to modify this behavior and pilot comments from simulation sessions continued to be negative, it was decided that the research controller would be modified so the lateral and directional axes would be decoupled in the research controller. This was accomplished by using a $\beta$-dot classical controller for the yaw axis, while continuing to use the original dynamic inverse control for the pitch and roll axes.

The research controller is therefore a hybrid controller using dynamic inversion in the longitudinal and lateral axes, with a classical control used in the directional axis. This modification was necessary in order to obtain reasonable flying qualities in the presence of a simulated failure.

\section{Adaptive Neural Network}

The neural network providing the online adaptation within the Gen 2 control scheme is known as sigma pi. The sigma pi neural network takes its name from the underlying equations of the network that sum $(\Sigma)$ the products $(\Pi)$ of the inputs to the neural network with its associated weights.

The weights of the neural network are determined by a training algorithm, also known as an adaptation or learning rule. The word 'learning' as used here means adjusting these weights so that the network has a valid relationship between the inputs and outputs. Weights of the neural network are calculated by using

- Commanded aircraft rates from the reference model

- PID error control and

- Adaptive control rates fed back from the neural network 
Equation 1 shows the calculation of the weights for the neural network as currently implemented in the Gen 2 system:

$$
\Delta \mathrm{W}=-G\left(U_{e} B+L\left|U_{e}\right| \mathrm{W}\right) \Delta \mathrm{t}
$$

where $\Delta \mathrm{W}$ are the weight calculations for the current time-step. Neural network weights (W) are the weights from the previous time-step. The time-step is $\Delta \mathrm{t}$, which is 0.0125 seconds ( $80 \mathrm{~Hz}$ rate). The adaptation gain is $G$, which is sometimes called the learning rate. The error compensation is $\mathrm{U}_{\mathrm{e}}$. Basis functions are $B$, which contain the squashing functions used in the sigma pi neural network. The dead band error used to stop learning when error is small is symbolized by $L$.

Values for $G$ and $L$ are configurable constants. The squashing function used in the neural network is a sigmoid function and has the form

$$
g(x)=\frac{\left(1-e^{-x}\right)}{\left(1+e^{-x}\right)}
$$

The adaptive neural network implemented for flight test is subdivided into three separate individual networks — one for each axis — pitch, roll, and yaw. The inputs to each individual neural network vary in number. The roll axis uses six inputs, the pitch axis has seven inputs, while the yaw axis has ten inputs. There are also an additional eight inputs (two inputs for each surface) that drive the antiwindup logic. A total of 31 inputs go to the three neural networks. The output of each neural network is an acceleration command that augments the control signal coming from the research controller for each axis.

\section{Antiwindup Logic}

Antiwindup flags act as a switch for the neural networks and are switched off when any surface is deflected to its limit. Three antiwindup flags are calculated with the eight surface deflections (four surfaces - aileron, stabilator, canard, and rudder - left and right for each surface) that are input into the neural network.

The pitch axis checks stabilator and canard deflections. The roll axis checks aileron and stabilator deflections. The yaw axis checks the rudder and canard deflections. Limits for each surface are listed in Table 1. below. 
Table 1. Surface limits used in antiwindup logic

\begin{tabular}{lcc}
\hline \hline \multicolumn{1}{c}{ Surface } & \multicolumn{1}{c}{ Limit } & Axis used \\
\hline Aileron & $-40 \mathrm{deg}<\delta_{\mathrm{a}}<40 \mathrm{deg}$ & roll \\
Stabilator & $-45 \mathrm{deg}<\delta_{\mathrm{s}}<15 \mathrm{deg}$ & roll, pitch \\
Canard & $-35 \mathrm{deg}<\delta_{\mathrm{c}}<15 \mathrm{deg}$ & pitch, yaw \\
Rudder & $-30 \mathrm{deg}<\delta_{\mathrm{r}}<30 \mathrm{deg}$ & yaw \\
\hline \hline
\end{tabular}

\section{Safety of Flight Monitors}

Because of the dynamic and unknown nature of neural network adaptation, additional monitors have been added to the system to help ensure safety of flight. One preexisting monitor will be used for the Gen 2 flights. The other monitors were developed specifically for the Gen 2 system to address specific safety issues and concerns. The function of these monitors is to down-mode the system whenever unsafe conditions exist during flight. Down-moding means that the aircraft flight computers switch from using the research control laws with adaptive neural networks, to using a set of standard or basic control laws (with no neural network adaptation present). A short description of each monitor follows below.

1. Envelope Monitor. The pick-a-limit (PAL) envelope monitor, which existed in the first IFCS system (Gen $1^{5}$ ), disengages the flight experiment if certain conditions or aircraft limits are exceeded during flight. These limits serve to keep the aircraft in a defined envelope with good known aircraft states. Gen 2 currently has two research flight envelopes defined - one more restrictive envelope that is a subset of a larger envelope. These two flight envelopes also aid in the build-up approach used during flight test.

2. Floating Limiter. A safety monitor called the neural network "floating limiter" has been added to the Gen 2 system. ${ }^{6}$ This safety monitor limits the value of the outputs of the neural networks. There is logic contained inside the neural network that freezes the weights (i.e. stops the learning) when the neural network output signals have been limited by the floating limiter. There is additional logic that causes the research controller to down-mode to a state that uses conventional and standard control laws when predefined hard limits are exceeded for the adaptive signals coming from the neural network.

3. Structural Safety Monitor. Because the neural networks may possibly move aircraft surfaces in unexpected or unconventional ways to adjust for simulated failures, a structural safety monitor is being implemented into the control room to monitor aircraft loads during flight. This monitor uses legacy code, which calculates the structural loads at 40 different locations on the aircraft. A set of flights, known as the Structural Loads Model Validation (SLMV) flights, are specifically dedicated to verifying the code that computes the loads. These flights are to be accomplished prior to the Gen 2 flights that use neural network adaptation. 


\section{Simulation Results}

The research controller, the neural networks, and the capability to run simulated failures during flight have been integrated into the NASA Dryden six-degree-of-freedom nonlinear simulation. Results from the simulation are presented in order to illustrate the experiment that is to be flown and highlight the benefits provided by the Gen 2 control system.

The capability to test the neural network in flight with two types of failures has been implemented for the Gen 2 research flights. One type of simulated failure, which represents an aerodynamic type of failure, inserts a multiplier onto the canard. The second type of simulated failure, which represents a surface failure, inserts a stabilator failure on either the left or right stabilator. Both failures have magnitudes that build up to maximum acceptable levels of failure magnitude and are to be tested in flight. The acceptable level of the failure magnitude was determined through the nonlinear simulation using $g$-transient guidelines provided by the pilots of the aircraft.

Because the nonlinear unpiloted (batch) simulation was used to run both failure cases, a simple autopilot needed to be inserted in the simulation in order to replicate the action a pilot would take after the aircraft had experienced a failure. The autopilot attempts to keep the aircraft at a wingslevel and constant altitude condition, but does not use the throttle settings in order to hold the Mach number. The equations used in the simulation for the autopilot are

$$
\begin{gathered}
\text { dap }=\text { dap }+c_{1} \varphi+c_{2} p \\
d e p=(-h d o t) c_{3}+c_{4}\left(h_{r e f}-h\right)
\end{gathered}
$$

where dap is the roll stick input, $\phi$ is the bank angle, $p$ is the body axis roll rate, dep is the pitch stick input, $h$ is the aircraft altitude, and $h d o t$ is the time rate-of-change of the aircraft altitude. The constants $c_{1}-c_{4}$ are gains for the autopilot. The gains to the autopilot were chosen so that the aircraft returned to a wings-level condition within 5 seconds of the failure onset, and held altitude to within $\pm 300 \mathrm{ft}$ of the altitude being maintained at the failure onset.

The simulation was used to compare two cases for each failure type. The first case run used the research controller with no neural network adaptation present. In the second case, the Gen 2 system was fully operational and neural network adaptation was present. In all cases, the simulated failure was commanded at ten seconds into flight and the autopilot was enabled. There was a time delay of four frames inserted into the simulation to replicate the time delays associated with the transfer of data between the computers on the vehicle via the 1553 data bus. All simulations cases are run for 50 seconds.

The third plot in figure 3 shows the response of the autopilot to a right stabilator failure, positive (trailing edge down) 4 degrees from trim, commanded at 10 seconds into the time history with 
no neural network augmentation present. The autopilot returns the aircraft to a wings-level state at the original flight condition. The fourth plot of figure 4 shows the right stabilator failure being commanded 10 seconds into the time history. Because the onset of the failure has a two-second delay to ensure that the pilot would have adequate time to trigger out of a failure condition, the failure actually occurs at 12 seconds. The right stabilator failure is inserted at the rate of 1-radian per second. Figure 5 shows that after the failure occurs at 12 seconds, and the aircraft returns to a wings-level condition, the aircraft flies with a $-0.1 \mathrm{~g}$ offset of $\mathrm{n}_{\mathrm{y}}$ and a 1 -degree offset in $\beta$, while $\mathrm{n}_{\mathrm{z}}$ eventually returns to the nominal value of $1 \mathrm{~g}$

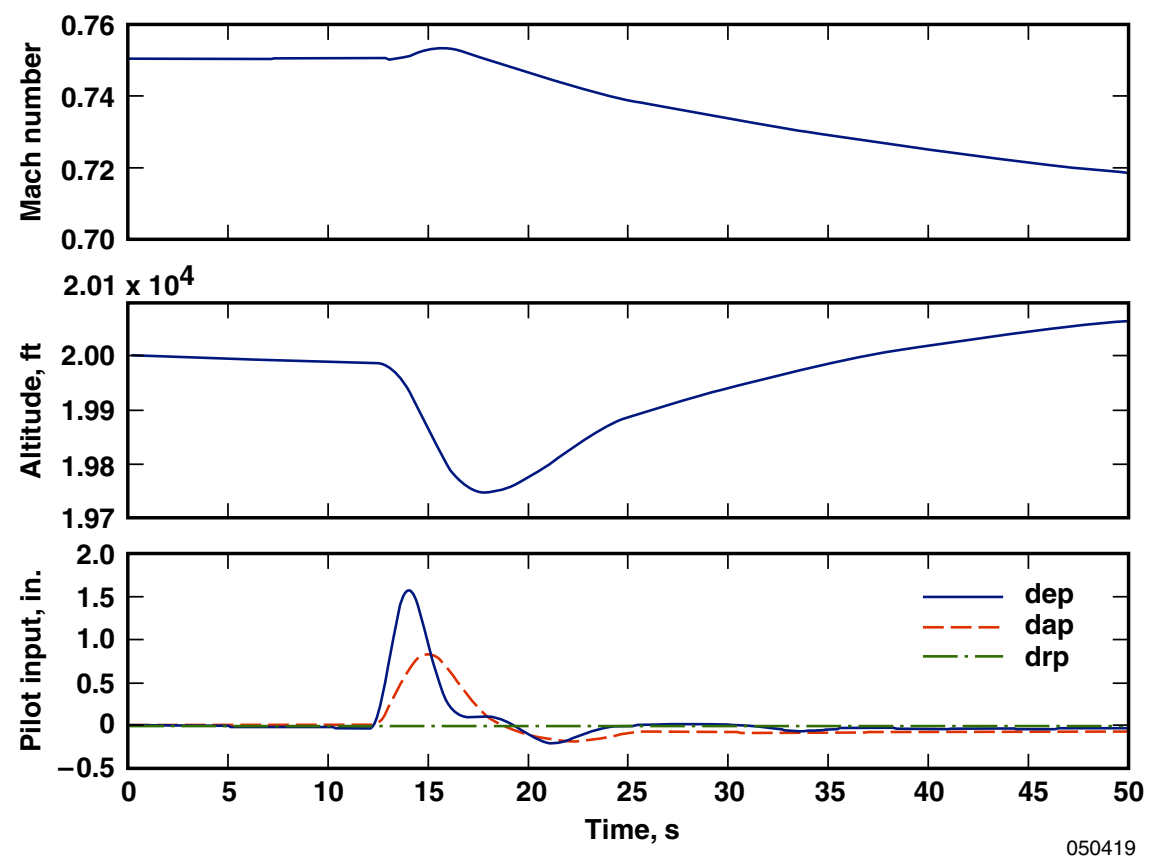

Figure 3. Aircraft response for right stabilator failure with no neural network adaptation.
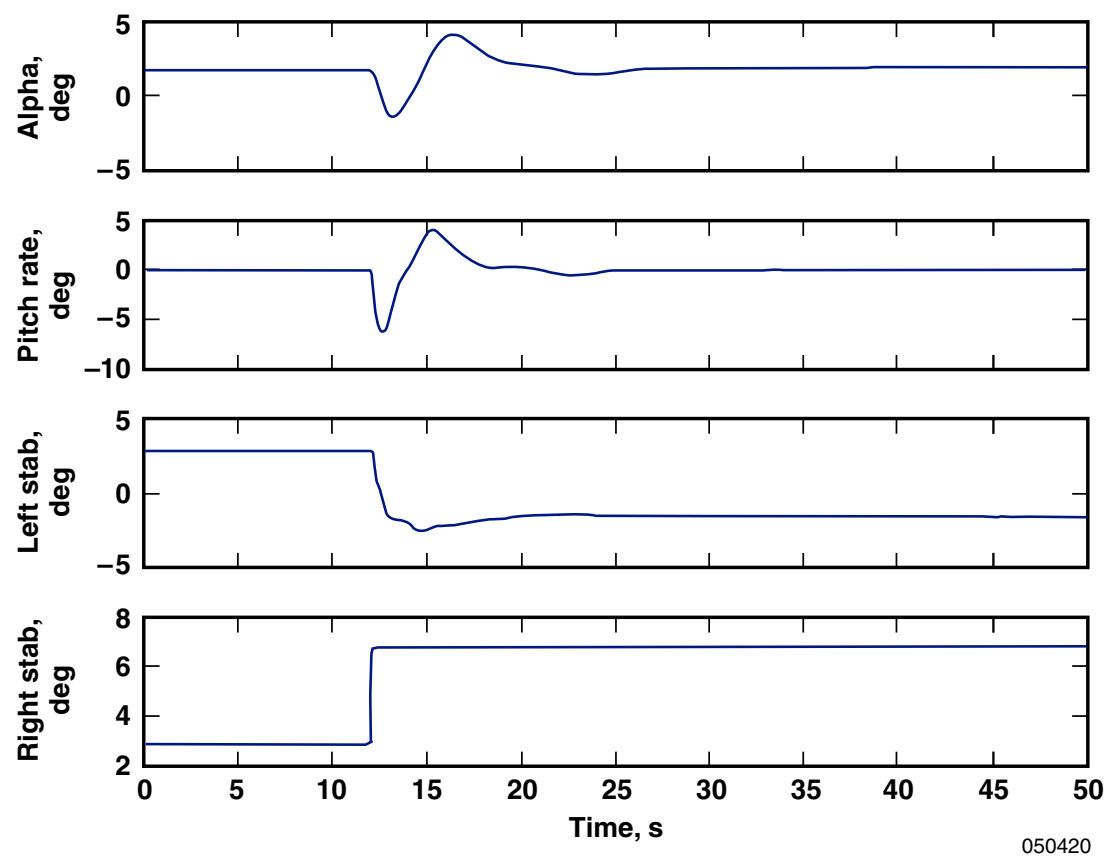

Figure 4. Stabilator positions for right stabilator failure with no neural network adaptation. 

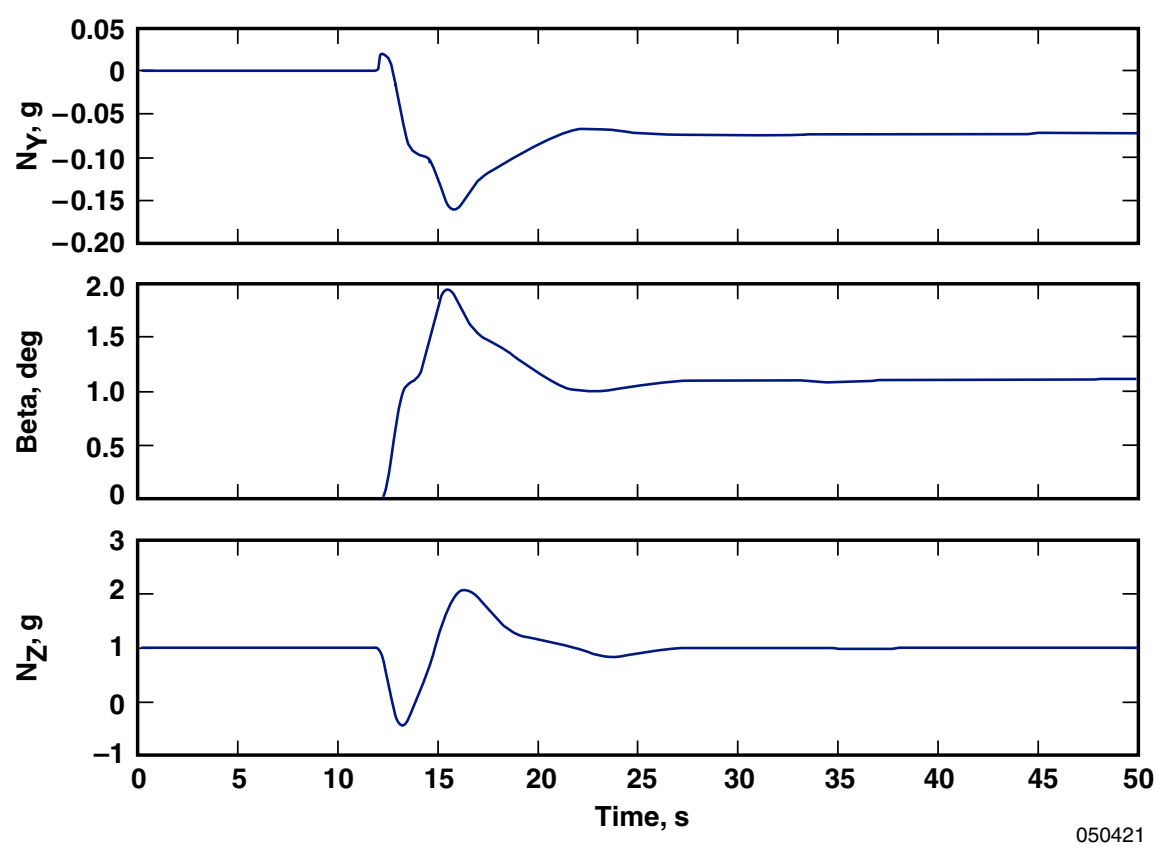

Figure 5. Aircraft response for right stabilator failure with no neural network adaptation.

Figure 6 shows the comparison plots of the autopilot inputs for the right stabilator failure case with and without neural network augmentation present. The autopilot gains used for both runs are identical. The neural network has the effect of lessening the autopilot input commands needed to restore the aircraft to 'wings-level, altitude hold' controlled flight. This in turn lowers the $g$ transients seen while the plane is returning to wings-level flight. The third plot of figure 7 shows a $0.3-g$ reduction in $n_{z}$. The third plot of figure 6 shows that while the Mach number trace is almost identical for the two cases, the fourth plot of figure 6 shows that the aircraft holds altitude better by almost 100 feet for the case with neural network adaptation turned on. 

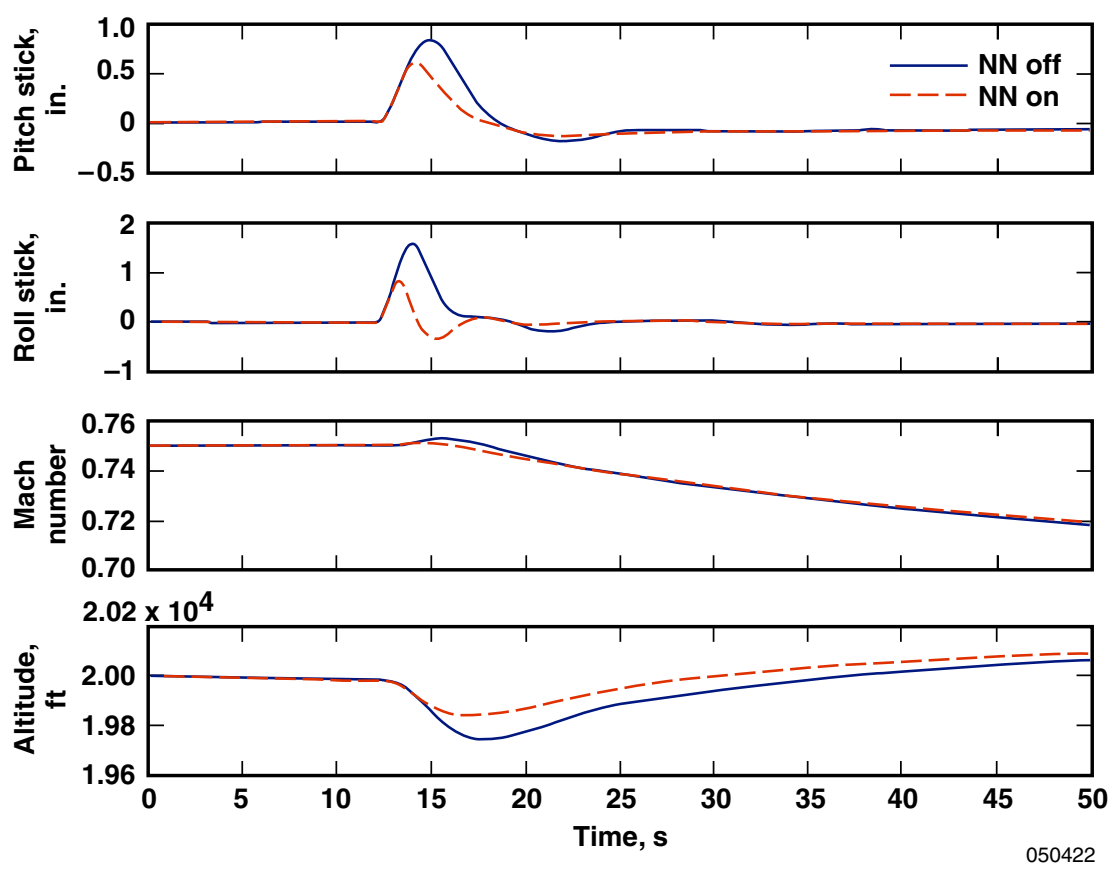

Figure 6. Comparison of inputs needed by autopilot for right stabilator failure.
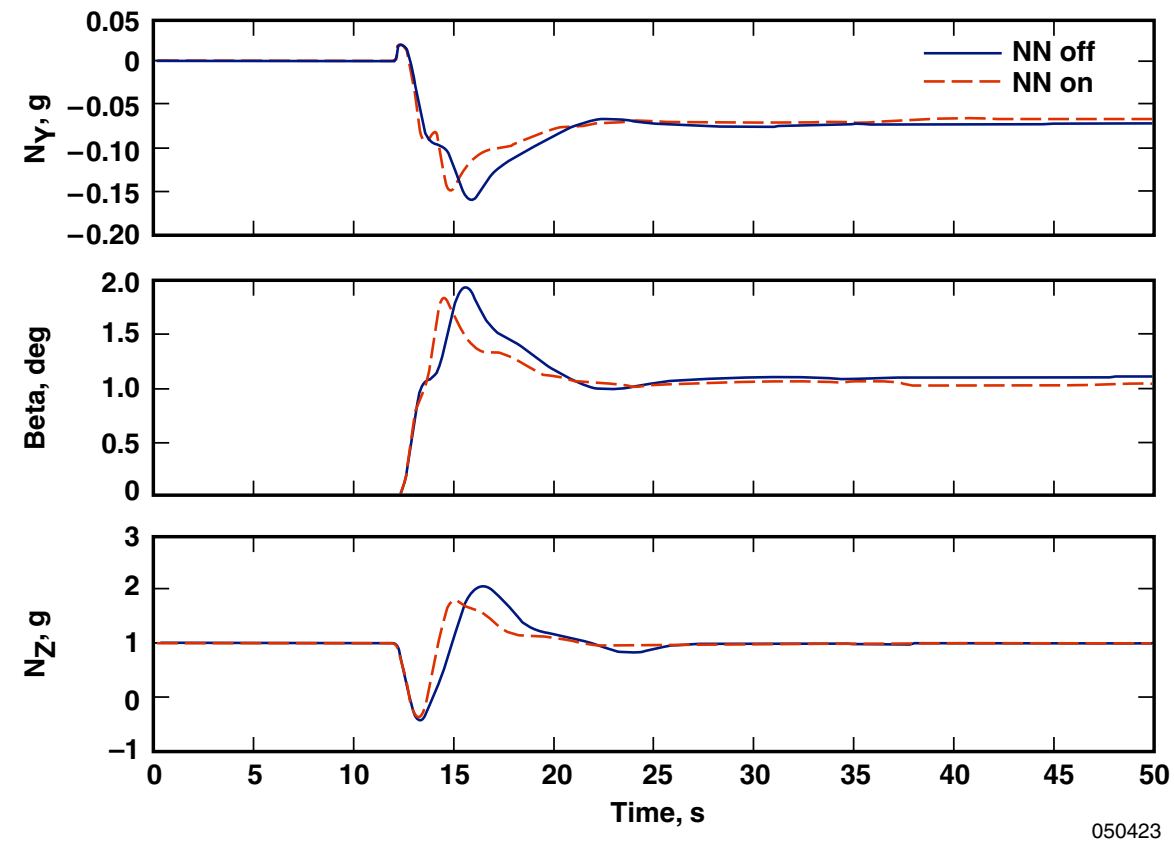

Figure 7. Comparison of $\mathrm{n}_{\mathrm{z}}$ seen during flight for right stabilator failure.

For the aerodynamic type of failure, a canard multiplier of - 0.6 was used in two different cases - one with no neural network adaptation, and one case with neural network adaptation turned on. Both cases use the same autopilot defined previously in eq. 3 and eq. 4. 
Figure 8 shows that the neural network adaptation assists the autopilot in restoring the aircraft to nominal flight. The research controller, in conjunction with the autopilot, is able to eventually control the aircraft (although the oscillations indicate that the autopilot gains may be too high for a failure of this type), with assistance from the neural network - less control inputs are needed and the aircraft returns to $1 \mathrm{~g}$ wings-level flight approximately 12 seconds earlier than in the case with no neural network adaptation present figure 9. Both failure cases demonstrate that the neural network is able to assist the research controller and autopilot, return the vehicle to nominal flight with lower $n_{z}$ transients, and in a shorter time period.

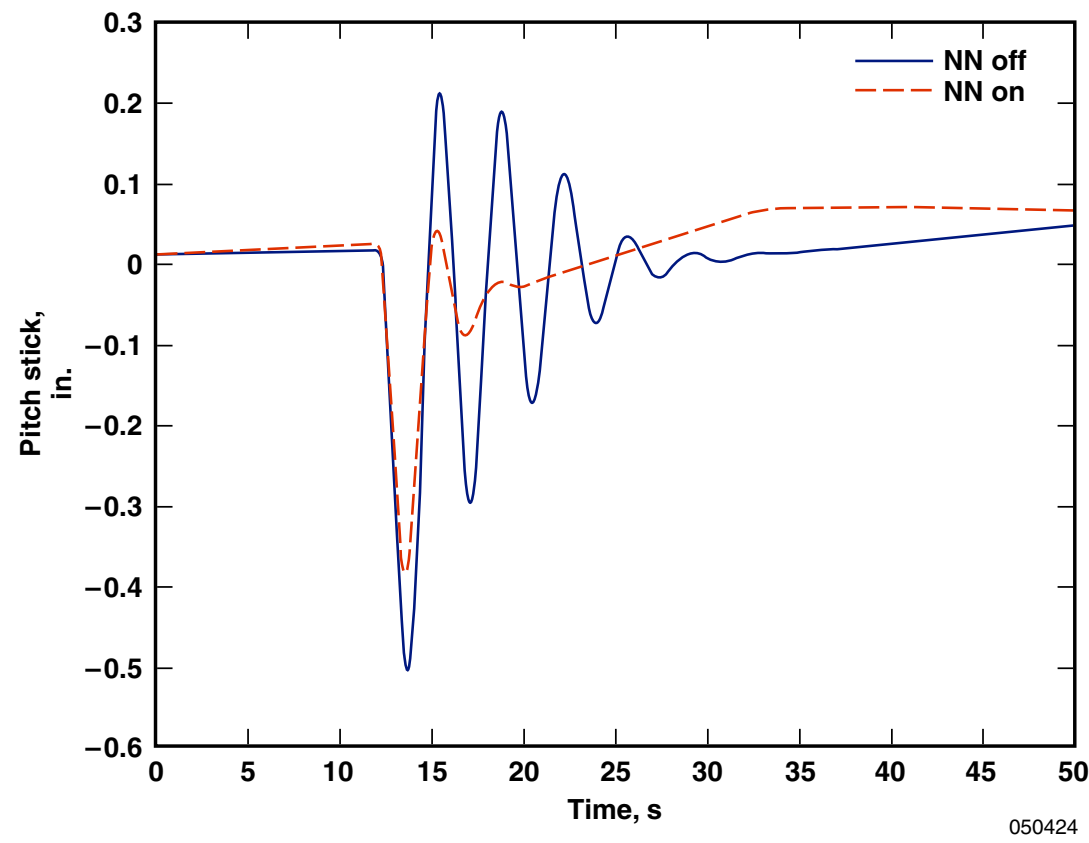

Figure 8. Comparison of pitch stick autopilot inputs for canard multiplier failure.

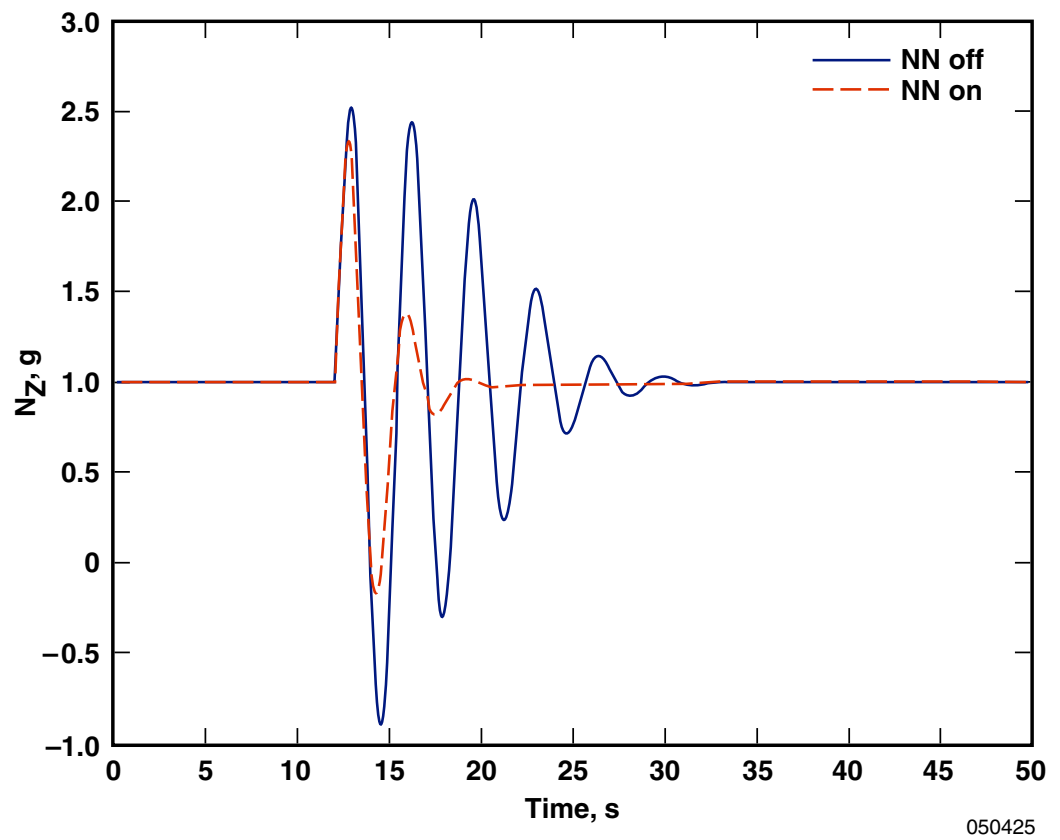

Figure 9. Comparison of $n_{z}$ seen during flight for canard multiplier failure. 


\section{SUMMARY}

This report describes the architecture of a research controller and neural network that has been implemented as part of the Intelligent Flight Control System project for flight testing on a modified NASA F-15 aircraft. The research controller used is a hybrid controller that uses dynamic inverse control for the pitch and roll axes, while using a classical $\beta$-dot controller for the yaw axis. This neural network used is a direct adaptive control algorithm that attempts to drive the error to zero between the reference model and the actual aircraft states. The neural network generated three adaptive control signals that augment the control signals provided by the research controller and PID gains to provide online adaptation to simulated failures in flight. Issues and concerns raised as a result of the implementation of the second generation (Gen 2) system on the aircraft for flight test are discussed, as are solutions which have been implemented for flight testing.

Simulation results that illustrate the Gen 2 flight experiment are shown. Benefits of the neural network are highlighted for two different types of simulated failure cases, a stabilator failure and a canard multiplier bias. Both failure cases demonstrate how the neural network is able to assist the research controller and autopilot return the vehicle to nominal flight with lower normal acceleration transients and in a shorter time period. These cases show both the benefits of the Gen 2 flight control system and the results expected to be obtained from flight test. The Gen 2 system is currently scheduled for flight test in the fall of 2005.

Dryden Flight Research Center

National Aeronautics and Space Administration

Edwards, California, August 25, 2005 


\section{REFERENCES}

1. Smolka, James W., et al., "F-15 ACTIVE Flight Research Program," 1996 Society of Experimental Test Pilots Fortieth Symposium Proceedings, September 1996, pp. 112-145.

2. Kim, Byoung S., and Anthony J. Calise, "Nonlinear Flight Control Using Neural Networks," Journal of Guidance, Control, and Dynamics, Vol. 20, No. 1, January-February 1997.

3. Blake, Matthew W., "The NASA Advanced Concepts Flight Simulator: A Unique Transport Aircraft Research Environment," AIAA-96-3518-CP, 1996.

4. Kaneshige, John, John Bull, and Joseph J. Totah, "Generic Neural Flight Control and Autopilot System," AIAA Guidance, Navigation, and Control Conference and Exhibit, AIAA-2000-4281, August 2000.

5. Williams-Hayes, Peggy S., Selected Flight Test Results for Online Learning Neural Network-Based Flight Control System, NASA/TM-2004-212857, December 2004.

6. Perhinschi, Mario J., Marcello R. Napolitano, Giampiero Campa, Heather E. Burke, Richard R. Larson, and John Burken, "Design and Testing of a Safety Monitor Scheme on the NASA Gen_2 IFCS F-15 Flight Simulator," AIAA-2004-6284, September 2004. 
The public reporting burden for this collection of information is estimated to average 1 hour per response, including the time for reviewing instructions, searching existing data sources, gathering and maintaining the data needed, and completing and reviewing the collection of information. Send comments regarding this burden estimate or any other aspect of this collection of information, including suggestions for reducing this burden, to Department of Defense, Washington Headquarters Services,

Directorate for Information Operations and Reports (0704-0188), 1215 Jefferson Davis Highway, Suite 1204, Arlington, VA 22202-4302. Respondents should be aware that notwithstanding any other provision of law, no person shall be subject to any penalty for failing to comply with a collection of information if it does not display a currently valid OMB control number.

PLEASE DO NOT RETURN YOUR FORM TO THF ABOVE ADDRESS
1. REPORT DATE (DD-MM-YYYY)
2. REPORT TYPE
3. DATES COVERED (From - To)
10-11-2005
Technical Memorandum

4. TITLE AND SUBTITLE

Flight Test Implementation of a Second Generation Intelligent Flight Control System

5a. CONTRACT NUMBER

5b. GRANT NUMBER

5c. PROGRAM ELEMENT NUMBER

6. AUTHOR(S)

Peggy S. Williams-Hayes

5d. PROJECT NUMBER

5e. TASK NUMBER

5f. WORK UNIT NUMBER

7232700 SE PR 00 GN2

\section{PERFORMING ORGANIZATION NAME(S) AND ADDRESS(ES)}

8. PERFORMING ORGANIZATION

NASA Dryden Flight Research Center REPORT NUMBER

P.O. Box 273

Edwards, California 93523-0273

H-2626

9. SPONSORING/MONITORING AGENCY NAME(S) AND ADDRESS(ES)

National Aeronautics and Space Administration

Washington, DC 20546-0001

NASA

11. SPONSORING/MONITORING REPORT NUMBER

NASA/TM-2005-213669

\section{DISTRIBUTION/AVAILABILITY STATEMENT}

Unclassified -- Unlimited

Subject Category -- 08

Availability: NASA CASI (310) 621-0390

Distribution: Standard

\section{SUPPLEMENTARY NOTES}

Also presented at Infotech@Aerospace conference

\section{ABSTRACT}

The NASA F-15 Intelligent Flight Control System project team has developed a series of flight control concepts designed to demonstrate the benefits of a neural network-based adaptive controller. The objective of the team was to develop and flight-test control systems that use neural network technology, to optimize the performance of the aircraft under nominal conditions, and to stabilize the aircraft under failure conditions. Failure conditions include locked or failed control surfaces as well as unforeseen damage that might occur to the aircraft in flight. The Intelligent Flight Control System team is currently in the process of implementing a second generation control scheme, collectively known as "Generation 2" or "Gen 2," for flight testing on the NASA F-15 aircraft. This report describes the Gen 2 system as implemented by the team for flight test evaluation. Simulation results are shown which describe the experiment to be performed in flight and highlight the ways in which the Gen 2 system meets the defined objectives.

\section{SUBJECT TERMS}

Adaptive control, F-15 aircraft, Flight control, Fight safety, Flight test, Neural networks, Simulation

\begin{tabular}{|c|c|c|c|c|c|}
\hline \multicolumn{3}{|c|}{ 16. SECURITY CLASSIFICATION OF: } & \multirow{3}{*}{$\begin{array}{l}\text { 17. LIMITATION OF } \\
\text { ABSTRACT }\end{array}$} & \multirow{3}{*}{$\begin{array}{l}\text { 18. NUMBER } \\
\text { OF } \\
\text { PAGES }\end{array}$} & \multirow{2}{*}{$\begin{array}{l}\text { 19a. NAME OF RESPONSIBLE PERSON } \\
\text { STI Help Desk (email: help@sti.nasa.gov) }\end{array}$} \\
\hline a. REPORT & b. ABSTRACT & c. THIS PAGE & & & \\
\hline & & & & & 19b. TELEPHONE NUMBER (Include area code) \\
\hline $\mathrm{U}$ & $\mathrm{U}$ & $\mathrm{U}$ & UU & 19 & (301) 621-0390 \\
\hline
\end{tabular}

